\title{
Compression therapy in venous diseases: current forms of compression materials and techniques
}

\author{
Andrzej Berszakiewicz ${ }^{1,2}$, Aleksander Sieroń ${ }^{3}$, Zbigniew Krasiński $^{4}$, Armand Cholewka $^{5}$, Agata Stanek ${ }^{3}$ \\ ${ }^{1}$ Department of Internal Medicine, Angiology and Physical Medicine, Specialist Hospital No. 2, Bytom, Poland \\ ${ }^{2}$ Fresenius Dialysis Centre No. 38 in Oswiecim, Fresenius Nephrocare Polska, Oswiecim, Poland \\ ${ }^{3}$ Department of Internal Medicine, Angiology and Physical Medicine, School of Medicine with the Division of Dentistry in Zabrze, \\ Medical University of Silesia, Bytom, Poland \\ ${ }^{4}$ Department of General and Vascular Surgery, Poznan University of Medical Sciences, Poznan, Poland \\ ${ }^{5}$ Department of Medical Physics, Chelkowski Institute of Physics, University of Silesia, Katowice, Poland
}

Adv Dermatol Allergol 2020; XXXVII (6): 836-841

DOI: https://doi.org/10.5114/ada.2019.86991

\begin{abstract}
Compression therapy (CT) is an established treatment method in chronic venous disease (CVD). The paper presents information on different CT forms with indications and contraindications based on expert consensuses from recent years. A high prevalence of CVD implies continuous development of compression materials, systems and techniques as well as measurement methods. The article aims at reviewing available literature on the development of compression therapy techniques.
\end{abstract}

Key words: compression therapy, chronic venous diseases, indications, contraindications.

\section{Compression therapy forms}

Compression therapy encompasses the use of hosiery, bandages, intermittent pneumatic compression and complex compression systems. Different types of materials of varying elasticity are used together. Cushions, pads, plaster-type bandages, drugs (such as zinc oxide), foam and gel dressings are also used in order to ensure best possible outcomes and highest achievable quality of life [1].

The subsequent part of the paper presents basic categories of currently used compression products and indications for their use.

\section{Medical compression hosiery}

Medical compression hosiery $(\mathrm{MCH})$ is manufactured using elastic textiles. They can be flat knit or circular knit. Flat knit textiles are thicker and stiffer. The final product needs to be sewn together. The circular knit textiles are thinner, more delicate and less stiff, with the final product of a cylindrical shape. Both methods enable manufacturing of standard and non-standard hosiery products of different lengths: knee-length socks, stockings or tights. Flat knit is the preferred manufacturing technique of products intended for patients with leg deformity [2, 3]. The selection criteria include the compression at the ankle level and material stiffness. Both parameters are determined by the manufacturer [4]. Historically, MCH were chosen based on a compression class. However, considering significant differences in compression values between these classes in different countries, a pressure range (in $\mathrm{mm} \mathrm{Hg}$ ) exerted by the product at the ankle level assessed in vitro was proposed as a more uniform criterion [5-7]. Currently, there are several compression hosiery classification systems. The most common one is the RAL-GZG classification used for medical compression hosiery certification. The two remaining ones include the CEN classification and the simplified ICC classification (Table 1). There is a lack of agreement on which classification should be universally applied. The following recommendations are commonly supported: - the guiding value is the pressure range rather than the compression class;

- pressure ranges should be assessed in vitro [8].

Furthermore, the manufacturers of compression hosiery are required to provide compression profiles [9]. These can be either graduated elastic compression stockings (GECS) with a decreasing compression profile or progressive elastic compression stockings (PECS) with a negative compression gradient. GECS are the standard compression therapy. Graduated elastic compression stockings (GECS) provide a decreasing pressure profile from distal (B point) to proximal (degressive gradient),

Address for corresponcence: Prof. Agata Stanek MD, PhD, Department of Internal Diseases, Angiology and Physical Medicine, Medical University of Silesia, 15 Batorego St, 41-902 Bytom, Poland, phone/fax: +48 32 7861630, e-mail: astanek@tlen.pl Received: 4.02.2019, accepted: 9.04.2019. 
Table 1. Medical compression hosiery classification $[4,6,7]$

\begin{tabular}{lccc}
\hline Level of compression & \multicolumn{3}{c}{ Classification } \\
\cline { 2 - 4 } & $\begin{array}{c}\text { RAL standard/pressure range } \\
{[\mathrm{mm} \mathrm{Hg}]}\end{array}$ & $\begin{array}{c}\text { CEN pre-standard/pressure } \\
\text { range }[\mathrm{mm} \mathrm{Hg}]\end{array}$ & $\begin{array}{c}\text { ICC proposal/pressure range } \\
{[\mathrm{mm} \mathrm{Hg}]}\end{array}$ \\
\hline Light & $18-21$ & $10-14$ & $10-19$ \\
\hline Mild & $23-32$ & $15-21$ & $20-29$ \\
\hline Moderate & $34-46$ & $23-32$ & $30-39$ \\
\hline Strong & $>49$ & $34-46$ & $\geq 40$ \\
\hline Very strong & 214 & $\geq 49$ & \\
\hline
\end{tabular}

The pressure values provided are measured at the B1 point. CEN - Centre Europeen de Normalisation, RAL - Reichs Ausschuss für Lieferbedingungen (State Commission for Delivery Terms), ICC - International Compression Club.

mimicking physiological pressure distribution (Table 2). The PECSs provide a higher compression pressure over the $\mathrm{C}$ point. The pressure exerted at the $\mathrm{C}$ point should be about $50 \%$ higher than that at the B point [10]. As a result, PECSs are more effective in increasing the venous ejection fraction (EF). Unfortunately, just as GECSs, they are unable to restore normal EF, although their clinical effect on the EF is close to the one of inelastic bandages $[4,10]$. PECSs should be worn only during daytime activities and removed for resting and at night due to poor tolerance and the risk of increased oedema of distal, less compressed, leg segments. Currently PECSs are not available on the market [11]. The commonly used GECSs can be divided into thromboprophylaxis stockings (TPS) and medical compression stockings (MCS). The TPSs offer compression of 15-18 $\mathrm{mm} \mathrm{Hg}$ and they are indicated for use for bedridden or partly ambulant patients, as a part of oedema prevention. By reducing the resting vein diameter, TPSs increase venous flow, prevent venous stasis and thrombosis. Higher compression MCSs are indicated for patients with CVD and abnormal lymph drainage. Elastic compression stockings improve the calf muscle pump function, reduce the amount of both venous reflux and venous volume, in turn normalising ambulatory venous pressure in limbs with CVI [12]. Based on available research and recommendations (last reviewed in 2017), MCSs are recommended in specific clinical situations (Table 3) $[13,14]$.

The SOX trial, in 2013, showed that elastic compression stockings (ECS) did not prevent post-thrombotic syndrome (PTS) after a first proximal DVT [15]. Then, in 2016, the OCTAVIA study showed that 2 years of compression was more effective than 1 year [16]. Poorer adherence to treatment in the SOX trial was one possible reason for its negative result. In turn, the latest IDEAL DVT trial [17], which did not include an untreated control group, showed that individualized duration of compression stocking use was as effective as 2.5 years of persistent use after acute DVT. In addition, if one chose to use compression stockings in this setting, treatment could be limited to 1 year in selected patients.
Table 2. Graduated elastic compression stockings (GECS) - pressure distribution [10]

\begin{tabular}{llll}
\hline Measuring point & B & B1 & C \\
\hline Compression \% & 100 & $70-100$ & $50-70$ \\
\hline
\end{tabular}

Measuring point $B$ - ankle, measuring point $B 1-10-15 \mathrm{~cm}$ above the medial malleolus, measuring point $C$ - largest calf circumference.

Elastic stockings are still used for indications not supported by RCTs, either empirically or based on intuitive choices. For example, they are used as a part of prevention in patients with symptomatic or asymptomatic varicose veins $[3,5]$.

It should be noted that the therapeutic effect of MCSs depends on patient compliance [3]. MCSs should be put on in the morning and removed at bedtime. They should also be replaced after 3-6 months of use, as with use, the textiles lose their elastic properties [5].

\section{Compression bandages}

The key properties of compression bandages are included in the PLACE acronym: pressure, layers, components, and elastic properties. Compression bandages can be divided into long stretch bandages (LSBs) and short stretch bandages (SSBS), with the percentage of maximum stretch as compared to the original length being the main classifier. The LSBs have extensibility over $100 \%$ as compared to less than $100 \%$ offered by the SSBs [5]. The SSI of LSBs is low (below 10), whereas SSBs have a high SSI of over 10 [18]. The SSI measured under the layer of extremely inelastic bandage with zinc paste may be as high as 40 [19]. The LSBs generate comparable resting and standing interface pressure. Body position change to standing and muscle contractions only slightly elevate the generated pressure [20]. Due to their elastic properties, the compression does not decrease alongside the leg circumference [7]. SSBs provide low resting interface pressure which significantly increases in a standing position and calf muscle pump contractions generate high pressure spikes. Pressure differences increase alongside the tension force applied during bandaging. As a result, 
Table 3. Clinical indications for graduated elastic compression stockings (GECS) depending on the compression level at the B1 point $[3-5,13,14]$

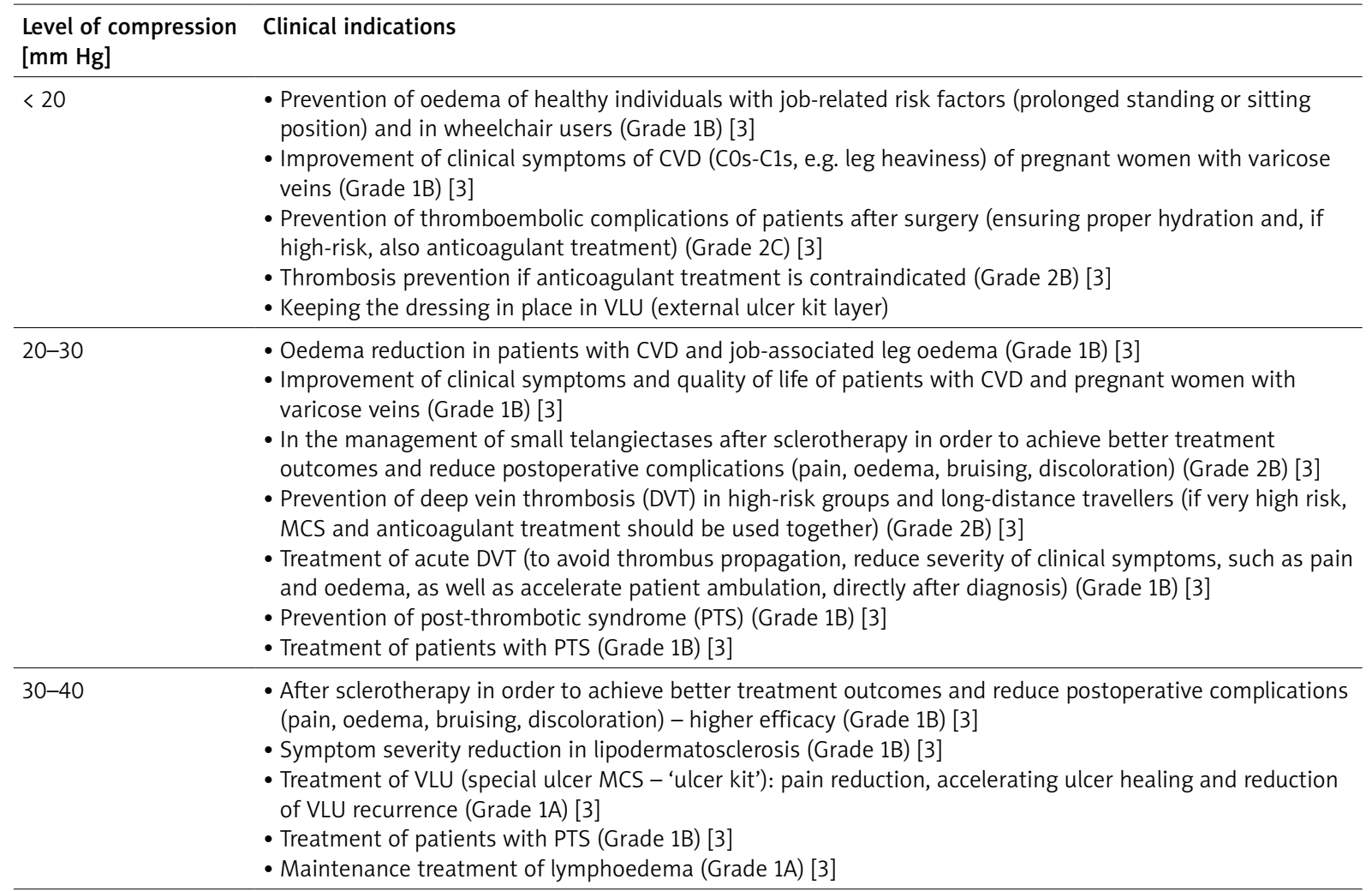

CVD - chronic venous disease, MCS - medical compression stockings, VLU - venous leg ulcer. Grade description of recommendations: $1 A$ - strong recommendation, high-quality evidence, $1 B$ - strong recommendation, moderate-quality evidence, $1 C$ - strong recommendation, very low-quality evidence, $2 A-$ weak recommendation, high-quality evidence, $2 B$ - weak recommendation, moderate-quality evidence, $2 C$ - weak recommendation, very low-quality evidence.

the massaging effect is exerted during walking [7, 13, 18, 20, 21]. Furthermore, compression safety is ensured, especially in patients with lower extremity artery disease. Comparable compression profiles can also be achieved with multilayer bandaging or complex compression systems (composed of elastic bandages and stiff pads or patches) [5]. Using multilayer bandaging or complex compression systems increases the stiffness and SSI [19]. Applying each additional layer increases the pressure by over $50 \%$ of the value of its single layer [7]. The stiffness also increases as a result of friction between the individual bandage layers [20]. It is particularly true for adhesive bandages which attach to the surface they are applied on and cohesive bandages which have low adhesive properties with a high binding force between the individual layers. These properties enable achieving high interface pressure, sufficient to prevent pain and bruises after surgery and endovascular procedures. The properties of adhesive bandages facilitate thigh bandaging [5]. Unlike the compression hosiery, which exerts sustained manufacturer-declared interface pressure, the pressure generated by the bandage depends on skills and experience of the person to apply it, bandaging technique, tension force and number of layers. Whereas patients can ap- ply LSBs independently, with SSBs, the help of a trained healthcare professional or a family member is required [20]. Unfortunately, only 10\% achieve the target interface pressure $[19,22]$. The most common error is overly loose application, typically seen with SSBs, which - even with full initial stretch - tend to lose their haemodynamic efficacy within the first hours following application, as a result of leg oedema reduction [3, 23]. As soon as $2 \mathrm{~h}$ following SSB application, the interface pressure drops by approximately $30 \%$. SSBs should be reapplied after $24 \mathrm{~h}$ by which the interface pressure has already halved $[14,24]$. In order to maintain the target interface pressure, new technological solutions are introduced, such as compression bandages with printed shapes (ovals or rectangles) which turn into circles or squares once target pressure is applied, or those with line indicator systems (longitudinal or transverse) which ensure sustained pressure and equal layer overlaps. Thus, smart bandages are used, into which silver strain gauge transducers are knitted, which enable real time measurement of interface pressure $[18,22,25]$. Even though, their application varies and the interface pressure values can only be approximated. There are no specific recommendations as to the bandaging technique. Application in a figure-eight 
Table 4. Compression bandaging: compression levels [5, 13]

\begin{tabular}{lcccc}
\hline Grade $[\mathrm{mm} \mathrm{Hg}]$ & $<20$ & $20-39$ & $40-59$ & $\geq 60$ \\
\hline Level of compression & Low & Moderate & High & Very high \\
\hline
\end{tabular}

Table 5. Indications for compression bandaging [1, 13, 21, 23, 24]

\begin{tabular}{|c|c|}
\hline Recommendation & Comment \\
\hline VLU treatment & $\begin{array}{l}\text { Recommendation for strong compression over } 40 \text { mm Hg using SSBs (very stiff, completely inelastic } \\
\text { bandages, for example Unna Boot with zinc paste), and multilayer compression systems including an } \\
\text { elastic component): faster granulation, reduced exudate, oedema and pain (Grade 1A) [21] }\end{array}$ \\
\hline $\begin{array}{l}\text { Treatment of mixed arterial } \\
\text { venous lower extremity ulceration }\end{array}$ & $\begin{array}{l}\text { Recommendation for compression of } 30-40 \mathrm{~mm} \mathrm{Hg} \text { using SSBs. Walking training to be used } \\
\text { alongside. Required measurements: ABPI, pressure measurement at the ankle }(>60 \mathrm{~mm} \mathrm{Hg}) \text { and } \\
\text { toe }(>30 \mathrm{~mm} \mathrm{Hg}) \text { levels }\end{array}$ \\
\hline Treatment of acute DVT & (Grade 1B) [21] \\
\hline Lymphoedema treatment & $\begin{array}{l}\text { Recommendation for very strong compression > } 60 \mathrm{~mm} \mathrm{Hg} \text {. SSBs or compression systems } \\
\text { composed of SSBs indicated (Grade 1B) [21] }\end{array}$ \\
\hline $\begin{array}{l}\text { Reduction of bleeding and } \\
\text { haematoma formation after } \\
\text { endovascular procedures }\end{array}$ & Recommendation for strong compression (Grade 1B) [21] \\
\hline
\end{tabular}

$A B P I$ - ankle-brachial pressure index, DVT - deep vein thrombosis, SSBS - short stretch bandages, VLU - venous leg ulcer.

pattern, in a spiral pattern or using Putter technique is possible. None of these techniques was shown to be superior to others. SSBs should remain in place for a few days, but they should be re-bandaged after $24 \mathrm{~h}$ (even twice a day) $[14,24]$. On the other hand, haemodynamically effective LSBs should be removed for the night due to poor tolerance by the patients [5, 20]. There are no uniform standards to regulate compression bandaging. Standardization was introduced in the UK only, where three types of bandages are available. Types 1 and 2 include lightweight conforming stretch and light support bandage used for retention and support, whereas type 3 is compression bandage [7]. Based on the ICC prestandards, four bandage compression levels have been distinguished in Europe based on the pressure ranges measured at the B1 point (Table 4) [5, 13]. Primarily, the need to exert standing pressure over $40 \mathrm{mmHg}$ is an indication for using compression bandages (Table 5) [5].

\section{Intermittent pneumatic compression}

Intermittent pneumatic compression (IPC) is a noninvasive technique with established efficacy in vascular pathologies [26]. It is a good alternative to other CT forms, especially when these are ineffective or cannot be used [14]. The IPC devices generate short high-pressure waves followed by low-pressure intervals. The intermittent nature and high frequency of pressure spikes enable generating pressure values of 120-180 mm Hg, as compared to only $60-70 \mathrm{~mm} \mathrm{Hg}$ generated by continuous compression [21]. Intermittent pneumatic compression devices are composed of inelastic sleeve- or boot-shaped chamber(s) and electrical pumps with gauges that pro- vide intermittent compression at predefined target pressures $[14,26]$. The compartments are inflated and deflated in an alternating manner. The compression force may be applied uniformly using a single chamber device, whereas the multi-chamber IPC may offer individual or sequential chamber inflation. Individual chamber inflation enables delivering predefined pressure to a specific area, for example distributing lower pressure over venous ulceration [26]. Sequential compression encompasses inflating the chambers one-by-one starting at the ankle and advancing proximally.

Sequential compression can be delivered as sequential pneumatic compression (SPC) or SCD RESPONSE Compression System, designed to apply sequential compression individually depending on venous return and venous outflow obstruction assessed using plethysmography [27]. SPC can be divided into alternate sequential compression (ASC) and simultaneous sequential compression (SSC) [28]. Actually, there are many SPC systems available with different pre-set inflation and deflation cycle times and frequently with a possibility to adjust cycle times. SCD RESPONSE Compression System enables individual adjustment of inflation/deflation cycle parameters and increasing the number of cycles per hour to approximately 100. It improves the ejection fraction volume per hour by $110 \%$ [27]. By improving calf muscle pump function, venous return and reducing venous stasis, IPC enhances venous blood flow preventing excessive venous pressure elevation. Better outcomes are achieved with higher compression levels, multi-chamber devices or sequential compression [26, 28, 29]. IPC can be used even in very severe arterial inflow abnormalities, but devices for arterial insufficiency are different. In addition, 
Table 6. Indications for intermittent pneumatic compression (IPC) $[3,5,21,26,28]$

\begin{tabular}{ll}
\hline Recommendation & Comment \\
\hline Local thrombosis prevention & $\begin{array}{l}\text { An alternative to or complements other thrombosis prevention methods used (Grade 1A) [21] } \\
\text { A method of choice in patients with high risk of haemorrhage }\end{array}$ \\
\hline VLU treatment & $\begin{array}{l}\text { To be used if no response to standard prolonged (6 months) CT } \\
\text { It reduces VLU size and healing duration and increases the percentage of healed VLUs [26] }\end{array}$ \\
\hline Lymphoedema treatment & $\begin{array}{l}\text { Adjunctive to conventional compression therapy, especially in non-ambulant patients or those with } \\
\text { lower extremity artery disease (Grade 1B) [21] }\end{array}$ \\
\hline DVT prevention & (Grade 1A) [21] \\
\hline CT-compression therapy, DVT-deep vein thrombosis, VLU-venous leg ulcer.
\end{tabular}

$C T$ - compression therapy, DVT - deep vein thrombosis, VLU - venous leg ulcer.

pressure and cycle times are different in the arterial and venous pump [24]. By generating high pressure spikes, IPC improves arterial inflow and microcirculation as it stimulates vascular endothelial cells as well as enhances production and release of vasoactive substances, such as nitric oxide. Additionally, it improves release of antiinflammatory substances, inhibits lymphocyte adhesion and platelet aggregation. Furthermore, it enhances local and systemic fibrinolytic activity of the plasma by inhibiting the plasminogen activator inhibitor-1 (PAI-1), and to a lesser extent by activating tissue plasminogen activator (tPA) [13]. As a result, capillary microcirculation within the skin and deeper tissues improves. Increasing the partial pressure of oxygen in tissue accelerates VLU healing [21, 26-28]. IPC reduces limb oedema and improves lymph drainage $[26,28]$. Its secondary effects include pain relief and improved quality of life [28]. There are also reports of the effect of IPC on improved bone density [21]. The indications for IPC are shown in Table 6. Despite multiple advantages, IPC cannot be used in all cases. It is not only due to contraindications to widely understood compression therapy [26]. IPC treatment is generally very safe and widely used. Complications of IPC are rare and only single reports are available. They resulted usually from misuse of IPC. Majority of trials with IPC did not report any significant adverse events [30].

When discussing IPC, hybrid devices (adaptive compression therapy) which combine sustained with intermittent pressure, should be mentioned. During activity periods, pneumatic pressure chambers compress the leg continuously at a constant interface pressure level. During sitting periods, the patient can switch to intermittent pressure. As a result, high efficiency of compression therapy is ensured [13].

\section{Adjustable Velcro compression devices}

Adjustable Velcro compression devices (AVCDs) are inelastic compression devices with high SSI. They can be applied by the patients after a short training course, without the help of healthcare professionals. After putting on, the patient adjusts the tension using velcro straps. The built-in pressure system and a measuring card ensure sustained interface pressure. This addresses the interface pressure drop early post-application $[13,14]$. Owing to their design and simplicity of use, AVCDs can be used by elderly individuals, patients with decreased muscle force, degenerative joint disease or after total knee replacement surgery associated with oedema [14]. The key advantages of AVCDs include their reusability, ability to trim and wash, safety and no need of involving healthcare professionals in their long-term use, which decreases treatment costs [14, 31]. AVCDs are indicated for treatment of venous oedema and lymphoedema both in early treatment stages, to reduce oedema, and in later treatment stages to maintain this effect, that is, to prevent recurrence of oedema [14, 31]. AVCDs are more effective in reducing oedema than SSBs. Compression of $40 \mathrm{~mm} \mathrm{Hg}$ with AVCDs corresponds to compression of $60 \mathrm{~mm} \mathrm{Hg}$ with SSBs. Furthermore, AVCDs are better tolerated by patients [14]. AVCDs are indicated in patients with VLUs who are unable to use bandages and show poor tolerance of medical compression hosiery [13]. They are also an alternative option in thrombosis prevention [31].

\section{Conclusions}

The forms of compression therapy discussed in this paper constitute the basics. The range of compression products is still expanding. New materials of novel properties, new compression systems as well as technologies to maintain and measure the interface pressure are being developed. Despite this progress, basic principles of compression therapy still apply. If clinical indications are present, any compression is always better than no compression. The level of compression should be adjusted to symptom severity and limited with the value of the minimum effective compression resolving symptoms of CVD [3]. Whereas the efficacy of elastic and inelastic materials in oedema is similar, the latter offer higher efficacy in improving venous haemodynamics [19]. Multicomponent compression systems, on the other hand, are the most suitable option for severe CVD. Elastic elements included in a design of such systems additionally improve their efficacy [1]. Compliance is the key to successful compression therapy. Non-compliance is usually associated 
with treatment failure, being one of risk factors for CVD progression [32]. However, the bottom line of any compression therapy is patient engagement, education and compliance.

\section{Acknowledgments}

The authors would like to thank Prof. Hugo Partsch for priceless remarks.

\section{Conflict of interest}

The authors declare no conflict of interest.

\section{References}

1. Mauck KF, Asi N, Elraiyah TA, et al. Comparative systemic review and meta-analysis of compression modalities for the promotion of venous ulcer healing and reducing ulcer recurrence. J Vasc Surg 2014; 60: 71S-90S.

2. MacGregor L, Partsch H, Mortimer P, et al. Lymphoedema Framework. Template for practice: compression hosiery in lymphoedema. MEP LTD, London, UK 2006; 1-4.

3. Rabe E, Partsch H, Hafner J, et al. Indication for medical compression stockings in venous and lymphatic disorders: an evidence- based consensus statement. Phlebology 2018; 33: 163-84.

4. Neumann HA, Partsch H, Mosti G, Flour M. Classification of compression stockings. Raport of the meeting of the International Compression Club. Int Angiol 2016; 35: 122-8.

5. Partsch H. Compression therapy: clinical and experimental evidence. Ann Vasc Dis 2012; 5: 416-22.

6. Rabe E, Partsch H, Junger M, et al. Guidelines for clinical studies with compression devices in patients with venous disorders of lower limb. Eur J Vasc Endovasc Surg 2008; 35: 494-500.

7. Partsch $\mathrm{H}$. The use of pressure change on standing a surrogate measure of the stiffness of a compression bandage. Eur J Vasc Endovasc Surg 2005; 30: 415-21.

8. Partsch H, Partsch B, Braun W. Interface pressure and stiffness of readymade compression stockings: Comparison of in vivo and in vitro measurements. J Vasc Surgery 2006; 44: 809-14.

9. Lattimer CR, Kalodiki E, Azzam M, Geroulakos G. Haemodynamic performance of low strength below knee graduated elastic compression stockings in health, venous disease, and lymphoedema. Eur J Vasc Endovasc Surg 2016; 52: 105-12.

10. Mosti G, Partsch H. Compression stockings with a negative pressure gradient have a more pronounced effect on venous pumping function than graduated elastic compression stocking. Eur J Vasc Endovasc Surg 2011; 42: 261-6.

11. Mosti G, Partsch $\mathrm{H}$. Improvement of venous pumping function by double progressive compression stockings: higher pressure over calf is more important than a graduated pressure profile. Eur J Vasc Endovasc Surg 2014; 47: 545-49.

12. Ibegbuna V, Delis KT, Nicolaides AN, Aina O. Effect of elastic compression stockings on venous hemodynamics during walking. J Vasc Surg 2003; 37: 420-5.

13. Partsch B, Partsch H. Compression therapy. In: VAS European Book on Angiology/Vascular Medicine. Catatalo M, Pecsvarady Z, Olinic D, et al. (eds). Aracne, Rome 2018; 687-99.

14. Mosti G, Cavezzi A, Partsch H, et al. Adjustable Velcro compression devices are more effective than inelastic bandages in reducing venous edema in the initial treatment phase: a randomized controlled trial. Eur J Vasc Endovasc Surg 2015; 50: 368-74.
15. Kahn SR, Shapiro S, Wells PS, et al. Compression stockings to prevent post-thrombotic syndrome: a randomised placebocontrolled trial. Lancet 2014; 383: 880-8.

16. Mol GC, Van de Ree MA, Klok FA, et al. One versus two years of elastic compression stockings for prevention of post-thrombotic syndrome (OCTAVIA study): randomised controlled trial. BMJ 2016; 353: i2691.

17. ten Hate-Coek AJ, Amin EE, Bouman AC, et al. Individualized versus standard duration of elastic compression therapy for prevention of post-thrombotic syndrome (IDEAL DVT): a multicenter, randomized, single-blind, allocation-concealed, noninferiority trial. Lancet Haematol 2018; 5: e25-33.

18. Mosti G, Partsch H. A new two compartment compression system turning an elastic bandage into an inelastic compression device: interface pressure, stiffness, and hemodynamic effectiveness. Eur J Vasc Endovasc Surg 2018; 55: 122-31.

19. Partsch H, Mosti G, Schuren J, Begnini JP. The Static Stiffness Index: an important parameter to characterize compression therapy in vivo. J Wound Care 2016; 25: 4-10.

20. Kocelj Leskovec N, Pavlović MD, Lunder T. A short review of diagnosis and compression therapy of chronic venous insufficiency. Acta Dermatovenerol Alp Pannonica Adriat 2008; 17: 17-21.

21. Partsch H, Flour M, Coleridge Smith P, et al. Indications for compression therapy in venous and lymphatic disease. Consensus based on experimental data and scientific evidence. Int Angiol 2008; 27: 193-219.

22. Damm J, Lundh T, Partsch H, Mosti G. An innovative compression system providing low, sustained resting pressure and high, efficient working pressure. Veins Lymph 2017; 6: 6627.

23. Mosti G, Partsch H. Inelastic bandages maintain their hemodynamic effectiveness over time despite significant pressure loss. J Vasc Surg 2010; 52: 25-31.

24. Mosti G, labichella ML, Partsch H. Compression therapy in mixed ulcers increases venous output and arterial perfusion. J Vasc Surg 2012; 55: 122-28.

25. Hutchinson J. Innovation in compression: smart bandage technology to improve bandage application and monitoring. Veins Lymph 2017; 6: 6631.

26. Berliner E, Ozbilgin B, Zarin DA. A systematic review of pneumatic compression for treatment of chronic venous insufficiency and venous ulcers. J Vasc Surg 2003; 37: 539-44.

27. Kakkos SK, Szendro G, Griffin M, et al. Improved hemodynamic effectiveness and associated clinical correlations of a new intermittent pneumatic compression system in patients with chronic venous insufficiency. J Vasc Surg 2001; 33: 915-22.

28. Koo KH, Choi JS, Ahn JH, et al. Comparison of clinical and physiological efficacies of different intermittent sequential pneumatic compression devices in preventing deep vein thrombosis: a prospective randomized study. Clin Orthop Surg 2014; 6: 468-75.

29. Yamany A, Hamdy B. Effects of sequential pneumatic compression therapy on venous blood velocity, refilling time, pain and quality of life in women with varicose veins: a randomized controlled study. J Phys Ther Sci 2016; 28: 191-7.

30. Feldman JL, Stout NL, Wanchai A, et al. Intermittent pneumatic compression therapy: a systematic review. Lymphology 2012; 45: $13-25$

31. Caprini J. A Commentary on Adjustable Velcro compression devices are more effective than inelastic bandages in reducing venous edema in the initial treatment phase: a randomized controlled trial. Eur J Vasc Endovasc Surg 2015; 50: 375.

32. Purwins S, Herberger K, Debus ES, et al. Cost-of-illness of chronic leg ulcers in Germany. Int Wound J 2010; 7: 97-102. 